Article

\title{
Simultaneous Determination of Fluorine and Chlorine in Marine and Stream Sediment by Ion Chromatography Combined with Alkaline Digestion in a Bomb
}

\author{
Yuhua Gao ${ }^{1}$, Xiaoyuan Wang ${ }^{2,3,4, *}$, Xianwen Fang ${ }^{5}$, Xuebo Yin ${ }^{2,4}$, Lu Chen ${ }^{1}$, Jianling Bi ${ }^{1}$, Yao Ma ${ }^{6,7,8}$ \\ and Shuai Chen $2,3,4$
}

check for updates

Citation: Gao, Y.; Wang, X.; Fang, X.; Yin, X.; Chen, L.; Bi, J.; Ma, Y.; Chen, $\mathrm{S}$. Simultaneous Determination of Fluorine and Chlorine in Marine and Stream Sediment by Ion

Chromatography Combined with Alkaline Digestion in a Bomb. J. Mar. Sci. Eng. 2022, 10, 93. https:// doi.org/10.3390/jmse10010093

Academic Editor: Nathalie Fagel

Received: 7 December 2021

Accepted: 4 January 2022

Published: 11 January 2022

Publisher's Note: MDPI stays neutral with regard to jurisdictional claims in published maps and institutional affiliations.

Copyright: (C) 2022 by the authors. Licensee MDPI, Basel, Switzerland. This article is an open access article distributed under the terms and conditions of the Creative Commons Attribution (CC BY) license (https:// creativecommons.org/licenses/by/ $4.0 /)$.
1 Shandong Institute of Geophysical \& Geochemical Exploration, Jinan 250013, China; wtyykcsgyh@163.com (Y.G.); chery1110029@163.com (L.C.); bijianling0305@163.com (J.B.)

2 Key Laboratory of Marine Geology and Environment, Institute of Oceanology, Chinese Academy of Sciences, Qingdao 266071, China; xbyin@qdio.ac.cn (X.Y.); Chenshuai@qdio.ac.cn (S.C.)

3 Laboratory for Marine Mineral Resources, Qingdao National Laboratory for Marine Science and Technology, Qingdao 266071, China

4 Center for Ocean-Mega Science, Chinese Academy of Sciences, Qingdao 266071, China

5 Qingdao Ecological Environment Monitoring Center, Qingdao 266003, China; zcfxw@126.com

6 College of Marine Resources and Environment, Hebei Normal University of Science and Technology, Qinhuangdao 066600, China; maoyaox@126.com

7 Hebei Key Laboratory of Ocean Dynamics, Resources and Environments, Qinhuangdao 066600, China

8 Qinhuangdao Key Laboratory of Marine Habitat and Resources, Qinhuangdao 066600, China

* Correspondence: wangxiaoyuan@qdio.ac.cn; Tel.: +86-532-82898541

\begin{abstract}
Fluorine and chlorine are important tracers for geochemical and environmental studies. In this study, a rapid alkaline digestion $(\mathrm{NaOH})$ method for the simultaneous determination of fluorine and chlorine in marine and stream sediment reference samples using ion chromatography is developed. The proposed method suppresses the volatilization loss of fluorine and chlorine and decreases the matrix effects. The results are in good agreement with fluorine $\sim 100 \%$, chlorine ranging from 90 to $95 \%$ of the expected concentrations. The detection limits of this method were $0.05 \mu \mathrm{g} / \mathrm{g}$ for fluorine and $0.10 \mu \mathrm{g} / \mathrm{g}$ for chlorine. This method is simple, economical, precise and accurate, which shows great potential for the rapid simultaneous determination of fluorine and chlorine in large batches of geological and environmental samples commonly analyzed for environmental geochemistry studies.
\end{abstract}

Keywords: fluorine and chlorine; marine and stream sediment; ion chromatography; alkaline digestion; high pressure bomb

\section{Introduction}

Fluorine and chlorine are of great interest in geological and environmental studies due to their special, highly mobile and volatile properties [1,2]. Fluorine is a minor constituent in a wide range of sedimentary minerals including phosphorites, phosphates, carbonates, silicates and clay minerals [3-6]. Chlorine is the dominant ligand that enables metal transport in the majority of hydrothermal solutions [6-8]. Thus, the content of fluorine, chlorine and ratios of element/ $\mathrm{Cl}$ in sediment can be used as tracers for chemical evolution of fluids and water/rock interactions in low temperature sediment alteration $[9,10]$ and high temperature hydrothermal systems [11-14], element recycling during subduction-related sediment melting [4,15], and early diagenesis of sediment [3]. Therefore, recent studies have focused on the precise determination of fluorine and chlorine in sediment. Several analytical techniques have been applied to the determination of fluorine and chlorine: by specific ion selective electrode [16-18], instrumental neutron activation analysis (INAA) [16], radiochemical neutron activation analysis (RNAA) [19-22], prompt gamma neutron activation 
analysis (PGNA) [23] or X-ray fluorescence spectrometry [24-27]. However, an ion selective electrode requires a rather complex preparation stage and the difficulties of other techniques are the requirement of special instruments and/or time-consuming processes [28]. Moreover, the detection limits of the determination by INAA or X-ray Fluorescence Spectrometry (XRFS) are generally too high, relative to usual abundances [29]. In contrast, ion chromatography, a compact and inexpensive instrument, is commonly used in many laboratories and is the most suitable method for sensitive and simultaneous determination of fluorine and chlorine [5,6,28-35]. However, it is difficult to quantitatively extract fluorine and chlorine from geological materials for ion chromatography analysis. So far, only a few methods have been used to extract fluorine and chlorine from geological samples, including pyrohydrolysis $[5,6,29,31,32]$, alkaline fusion $[5,17,28,30]$, microwave digestion [36], combustion [35] and $\mathrm{NH}_{4} \mathrm{HF}_{2}$ digestion with subsequent ammonium dilution [37]. However, the pyrohydrolysis method is not suitable for the analysis of a large batch of samples [37]; alkali fusion requires a high flux-to-sample ratio which results in high blank levels, total dissolved solids (TDS) content and matrix effects $[5,28]$, microwave digestion has poor recoveries caused by incomplete digestion of sediment samples containing zircon or other refractory minerals [38], and the $\mathrm{NH}_{4} \mathrm{HF}_{2}$ digestion method cannot extract fluorine from geological materials [37]. Recently, a high-pressure digestion technique has been generally applied [8,36,39-41]. However, there are no reports about the simultaneous determination of fluorine and chlorine in sediment using this technique.

In this paper, a rapid alkaline digestion method for the simultaneous determination of fluorine and chlorine in marine and stream sediment reference samples using the highpressure digestion bomb with a double inner arc seal design is described. The effects of the digestion parameters on the recoveries of fluorine and chlorine in sediment reference samples are described in detail. A small amount of the sample was digested, and the fluorine and chlorine were extracted completely. This method is practical and simple and can deal with a large number of samples simultaneously.

\section{Experimental}

\subsection{Instrumentation}

Experiments were carried out using ion chromatography (DX600, Dionex, CA, USA) at the Laboratory of Spartacus Testing Center, equipped with an anion exchange column in the suppression mode. Analytical conditions are reported in Table 1. Generally, the F- peak appeared at about 3.8 min after sample injection. Then, the $\mathrm{Cl}$ - peak appeared at about $4.7 \mathrm{~min}$ after the injection (Figure 1 ). One measurement cycle could be completed in $\sim 10$ $\min$.

Table 1. Instrumental operating parameters used for ion chromatography analysis.

\begin{tabular}{cc}
\hline & Operating Parameters \\
\hline Volume of Sample Injection Loop & $25 \mu \mathrm{L}$ \\
Column & IonPac AS14 \\
Column Size & $4 \mathrm{~mm} \times 250 \mathrm{~mm}$ \\
Eluent & $3.5 \mathrm{mmol} / \mathrm{L} \mathrm{Na}_{2} \mathrm{CO}_{3}+1 \mathrm{mmol} / \mathrm{L} \mathrm{NaHCO}_{3}$ \\
Detector & Suppressed conductivity detector \\
Flow Rate & $1.2 \mathrm{~mL} / \mathrm{min}$ \\
\hline
\end{tabular}




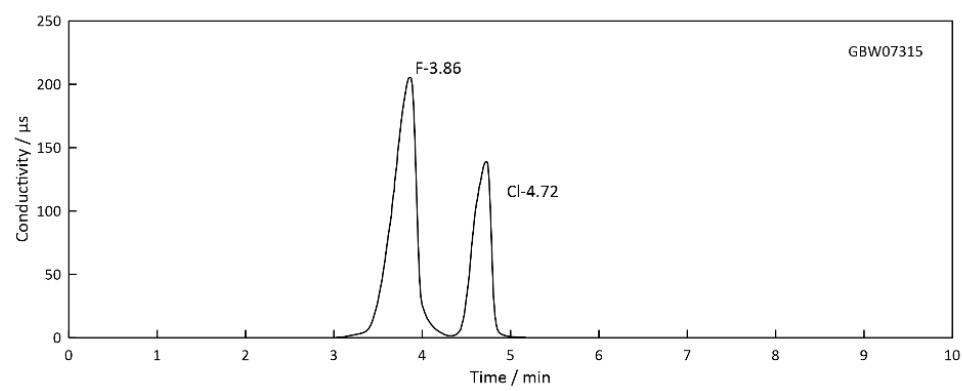

Figure 1. Chromatogram of marine sediment GBW07315.

\subsection{Reagents and Certified Reference Materials}

Alkaline digestion solution was prepared by diluting $\mathrm{NaOH}$ (AR, Aladdin, Shanghai, China) with pure water $(18.2 \mathrm{M} \Omega \cdot \mathrm{cm}$ grade). Eluent solution was prepared just before analysis by diluting $\mathrm{Na}_{2} \mathrm{CO}_{3}$ (AR, Sinopharm, Shanghai, China) and $\mathrm{NaHCO}_{3}$ (AR, Sinopharm, Shanghai, China) reagents with pure water. The calibration solutions were prepared by dilution from $1000 \mathrm{mg} / \mathrm{L}$ fluorine and chlorine standard solutions (National Research Center for Reference Materials, Beijing, China) with pure water. Three domestic reference materials GBW07315 (marine sediment from the CC area in the east pacific basin), GSD-9 (stream sediment from the Yangtze River) and GSD-10 (stream sediment from the catchment basin in Yishan, Guangxi Province) were used as reference samples. All these samples were in powder form with size less than $75 \mu \mathrm{m}$ as originally prepared. Reference GBW07315 was used to optimize the alkaline digestion temperature and time.

\subsection{Laboratory Ware}

A screw-top PTFE-lined, corrosive-resistant digestion bomb with a volume of $\sim 15 \mathrm{~mL}$ was used for this research (Figure 2). This bomb has a double inner arc seal design, the inner tank has an oval cross-section, the upper part of the inner tank plugs into the top of the lower part. The inner tank was pre-cleaned with $10 \% \mathrm{HNO}_{3}$ and heated to boiling for about $12 \mathrm{~h}$ at $120^{\circ} \mathrm{C}$, then rinsed with pure water.

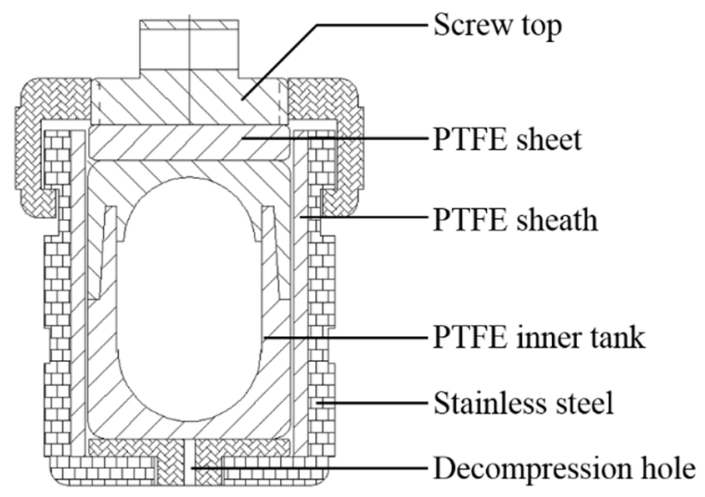

Figure 2. Sketch of the corrosive-resistant digestion bomb (Reproduced with permissions from Ref. [39], Copyright (C) 2018 Atomic Spectroscopy).

\subsection{Sample Preparation}

A total of $40 \mathrm{mg}$ aliquot of sample powder was accurately weighed into the PTFE bombs and $\mathrm{NaOH}$ was added. The sealed bombs were then placed in an electric oven at $240{ }^{\circ} \mathrm{C}$ for $12 \mathrm{~h}$. After cooling, $6 \mathrm{~mL}$ pure water was added, then the bombs were heated again in the electric oven at $180{ }^{\circ} \mathrm{C}$ for $12 \mathrm{~h}$. After cooling again, the sample solution was transferred to a $15 \mathrm{~mL}$ centrifuge tube and diluted to $10 \mathrm{~mL}$ with pure water. After centrifuging for $8 \mathrm{~min}$ at $3000 \mathrm{rpm}, 2 \mathrm{~mL}$ sample of the supernatant was transferred to a new polyethylene tube. The supernatant was measured by ion chromatography. 


\subsection{Calibration Curves and Limit of Detection}

Fluoride and chloride calibration curves in the range of $1-10 \mu \mathrm{g} / \mathrm{g}$ and $1-200 \mu \mathrm{g} / \mathrm{g}$ were prepared respectively by dilution from $1000 \mathrm{mg} / \mathrm{L}$ standard solutions (National Research Center for Reference Materials, Beijing, China) with pure water (Figure 3). The correlation coefficient $\left(\mathrm{R}^{2}\right)$ of the linear calibration is 0.9999 for fluorine and 0.9997 for chlorine, respectively. The method's limit of detection (LOD, three times the standard deviation of the $6 \% \mathrm{NaOH}$ blank solution for seven preparation blanks assuming a dilution factor of 250) for $\mathrm{F}$ and $\mathrm{Cl}$ were $0.05 \mu \mathrm{g} / \mathrm{g}$ and $0.10 \mu \mathrm{g} / \mathrm{g}$, respectively.
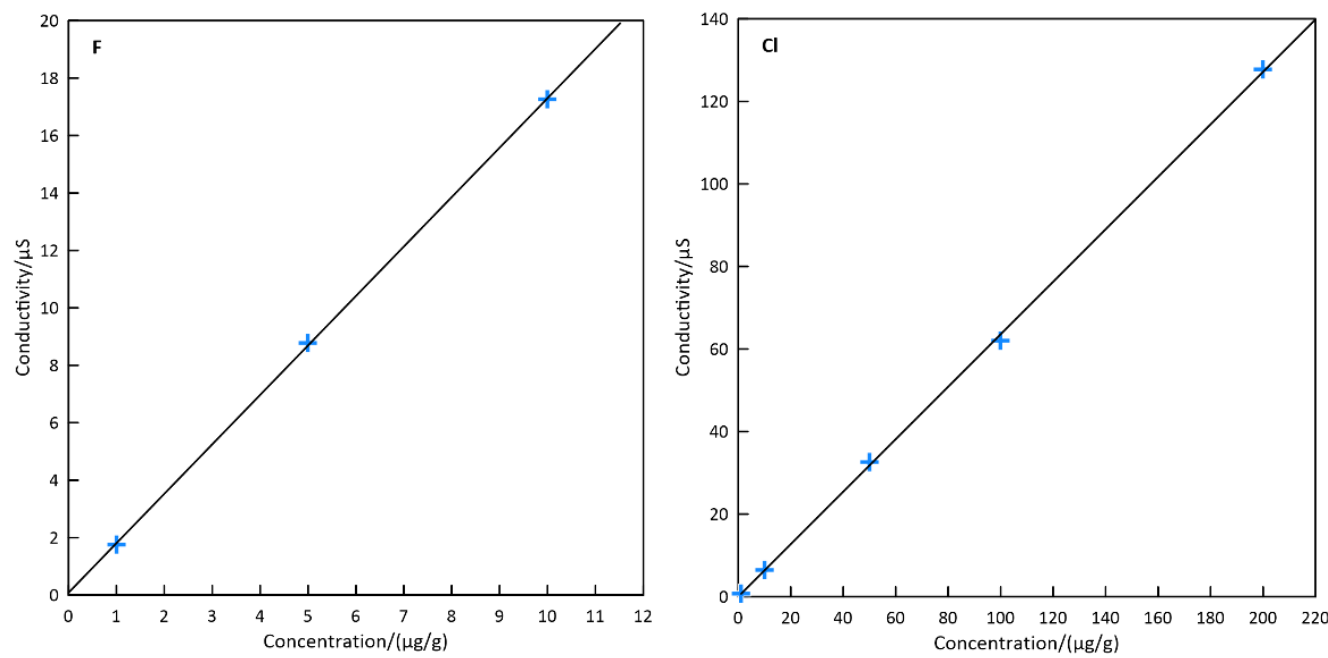

Figure 3. Fluoride and chloride calibration curves performed by ion chromatography.

\section{Results}

The measured concentrations of chlorine and fluorine were compared to the reference values provided for the standard material, GW07315, GSD-9 and GSD-10-1 (Table 2). Generally, the results are in good agreement with F- being 100\%, Cl ranging from 90-95\% of the expected concentrations. The relative standard deviation between replicates was $<6 \%$ and $<10 \%$ for fluorine and chlorine, respectively.

Table 2. Results for GBW07315, GSD-9-1 and GSD-10-1, and Comparison with Certified Data.

\begin{tabular}{ccccccc}
\hline & \multicolumn{2}{c}{ GWB07315 } & \multicolumn{2}{c}{ GSD-9-1 } & \multicolumn{2}{c}{ GSD-10-1 } \\
\hline & $\mathbf{F}(\mu \mathrm{g} / \mathrm{g})$ & $\mathbf{C l}(\boldsymbol{\mu g} / \mathbf{g})$ & $\mathbf{F}(\boldsymbol{\mu g} / \mathbf{g})$ & $\mathbf{C l}(\boldsymbol{\mu g} / \mathbf{g})$ & $\mathbf{F}(\boldsymbol{\mu g} / \mathbf{g})$ & $\mathbf{C l}(\boldsymbol{\mu g} / \mathbf{g})$ \\
\hline 1 & 1055 & 33,037 & 467 & 49 & 149 & 41 \\
2 & 1176 & 34,452 & 503 & 43 & 140 & 48 \\
3 & 1099 & 34,992 & 482 & 46 & 151 & 45 \\
4 & 1152 & 33,982 & 518 & 56 & 161 & 49 \\
5 & 1058 & 36,987 & 503 & 45 & 144 & 49 \\
6 & 1034 & 31,972 & 525 & 44 & 157 & 45 \\
7 & 1156 & 33,650 & 490 & 48 & 142 & 40 \\
Measured Average Value & 1104 & 34,153 & 498 & 47 & 149 & 45 \\
Reference Value & 1100 & $36,000 \pm 3000$ & $494 \pm 39$ & $52 \pm 11$ & $149 \pm 38$ & 50 \\
Relative Standard & $5.2 \%$ & $4.6 \%$ & $4.0 \%$ & $9.5 \%$ & $5.2 \%$ & $8.0 \%$ \\
Deviation & $100 \%$ & $95 \%$ & $101 \%$ & $90 \%$ & $100 \%$ & $90 \%$ \\
Accuracy & & & &
\end{tabular}

\section{Discussion}

\subsection{Effect of the Amount of $\mathrm{NaOH}$}

Although acid digestion has been commonly used for the decomposition of geological samples [38], mineral acids should be avoided to prevent losses of volatile halogens [37]. Alkaline fusion with $\mathrm{NaOH}$ can quantitatively extract fluorine [17] and chlorine [20-22] from geological materials, and the high-pressure digestion bomb requires a small amount of reagent, therefore $\mathrm{NaOH}$ was used as the digestion reagent. Figure 4 shows the agreements of $\mathrm{F}$ and $\mathrm{Cl}$ as a function of added $\mathrm{NaOH}$ amount for the digestion of $40 \mathrm{mg}$ of GBW07315. 
The agreements are expressed as ratios of the measured values relative to their reference values. It can be seen that $\mathrm{F}$ was completely recovered with $0.75 \mathrm{~mL} 6 \% \mathrm{NaOH}$, and the agreement for $\mathrm{Cl}$ was good with both $0.75 \mathrm{~mL} 6 \% \mathrm{NaOH}$ and $0.50 \mathrm{~mL} 6 \% \mathrm{NaOH}$. Thus, the adopted optimum amount is $0.75 \mathrm{~mL} 6 \% \mathrm{NaOH}$.

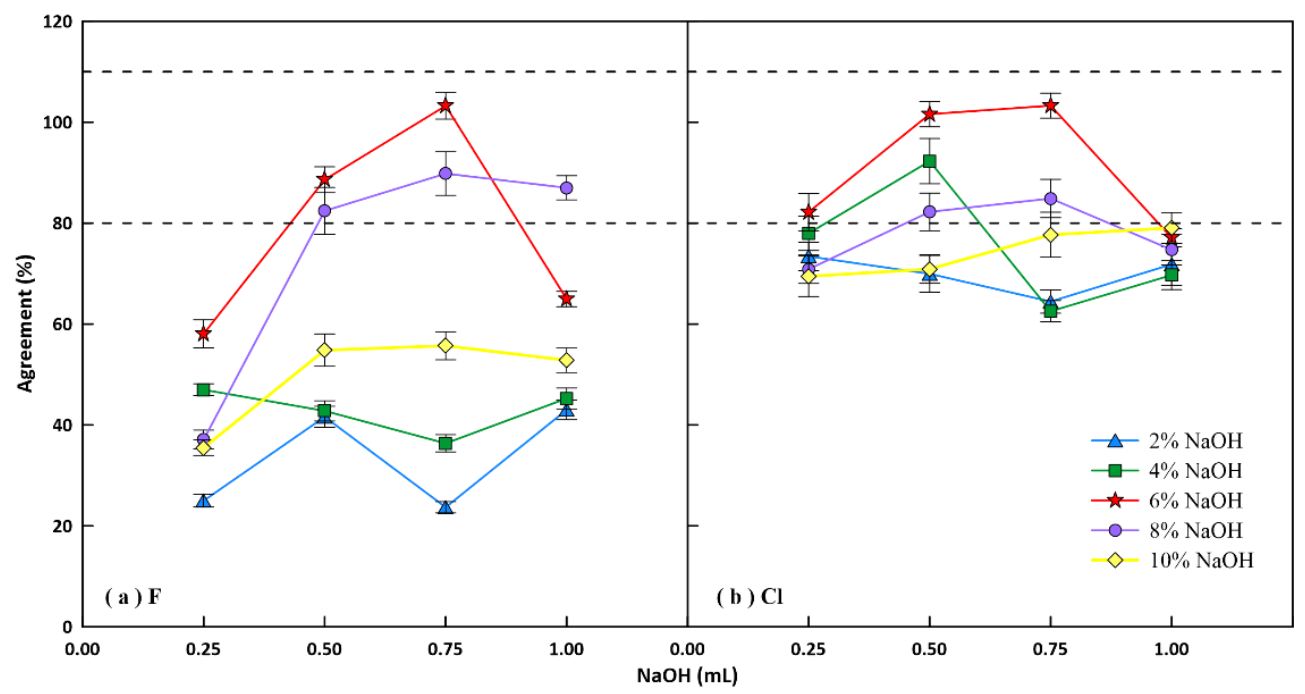

Figure 4. Agreement of (a) fluorine and (b) chlorine as a function of the amount of $\mathrm{NaOH}$. The dotted lines delimit recoveries between $80 \%$ and $110 \%$. The agreement is the ratio of the measured value relative to reference values. Error bars represent relative standard deviation $(n=3)$.

\subsection{Effect of Digestion Temperature}

Figure 5 illustrates the variation of the agreements for $\mathrm{F}$ and $\mathrm{Cl}$ in GBW07315 at different digestion temperatures $\left(150-260^{\circ} \mathrm{C}\right)$ with $0.75 \mathrm{~mL} 6 \% \mathrm{NaOH}$. The observation demonstrates that the digestion temperature is the critical factor for the complete recovery of $\mathrm{F}$ and $\mathrm{Cl}$. The recoveries of both $\mathrm{F}$ and $\mathrm{Cl}$ increased from $150{ }^{\circ} \mathrm{C}$ to $240{ }^{\circ} \mathrm{C}$ and they were completely recovered at $240{ }^{\circ} \mathrm{C}$ and $260^{\circ} \mathrm{C}$. Therefore $240^{\circ} \mathrm{C}$ was used as the optimum for further extractions. 


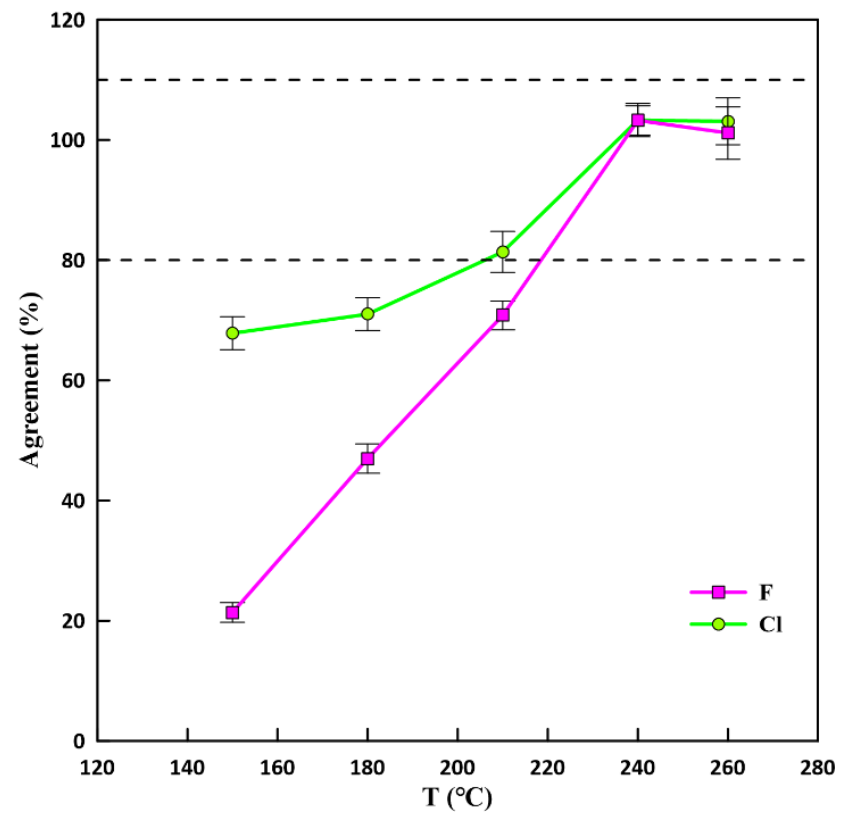

Figure 5. Agreement of fluorine and chlorine as a function of the digestion temperature with $0.75 \mathrm{~mL} 6 \% \mathrm{NaOH}$. The dotted lines delimit recoveries between $80 \%$ and $110 \%$. The agreement is the ratio of the measured value relative to reference values. Error bars represent relative standard deviation $(n=3)$.

\subsection{Method Efficiency}

The recovery of the pyrohydrolysis method is not stable [8], probably due to the loss of the halogens or the incomplete extraction during the pyrohydrolysis process [21,22]. In contrast, the digestion bomb used in this study has a double inner arc seal design, allowing the evaporating material from the top to the bottom without clinging onto the inner tank wall, which provides an effective circulation and suppresses the volatilization loss of fluorine and chlorine. The present method consumes a small amount of alkaline $(0.75 \mathrm{~mL} 6 \% \mathrm{NaOH}$ can extract fluorine and chlorine from $40 \mathrm{mg}$ sample completely) and decreases the matrix effects in comparison to the alkaline fusion method, which requires a large amount of flux and the matrix separation step leading to a high procedural blank $[5,28,30]$. The $\mathrm{NH}_{4} \mathrm{HF}_{2}$ digestion method has been proposed recently, which suppresses the volatilization loss of chlorine effectively owing to the formed ammonium salts with high boiling points, however, this method cannot determine fluorine and chlorine simultaneously [37]. In addition, compared to the complicated pyrohydrolysis, alkaline fusion and combustion methods $[5,6,17,28-32,35]$, the rapid alkaline digestion method is simple and can deal with a large batch of samples.

\section{Conclusions}

Our results show that $\mathrm{NaOH}$ digestion in a high-pressure bomb with double inner arc seal design can be used for the quantitative extraction of fluorine and chlorine in sediments. The proposed method is economical and requires a small amount of the sample and reagent. This effective and simple method has no contamination problems, with good accuracy, and shows great potential for the determination of fluorine and chlorine in large batches of geological and environmental samples.

Author Contributions: Y.G.-Conceptualization, Data curation, formal analysis, writing and editing; X.W.-Conceptualization, funding acquisition, writing and editing; X.F.-formal analysis; X.Y.Data curation, methodology, validation; L.C.-Data curation; J.B.-formal analysis; Y.M.-funding acquisition; S.C.-funding acquisition. All authors have read and agreed to the published version of the manuscript. 
Funding: This research was funded by the Strategic Priority Research Program of the Chinese Academy of Sciences (grant number XDB42020402), the National Natural Science Foundation of China, grant number 91958213); the Natural Science Foundation of Shandong Province (grant number ZR2020MD068; ZR2020QD069), Natural Science Foundation of Hebei Province (grant number D2021407001)

Institutional Review Board Statement: Not applicable.

Informed Consent Statement: Not applicable.

Data Availability Statement: Data can be obtained from the corresponding author.

Acknowledgments: The authors are most grateful for the detailed comments and suggestions provided by the reviewers.

Conflicts of Interest: The authors declare no conflict of interest.

\section{References}

1. Bonifacie, M.; Jendrzejewski, N.; Agrinier, P.; Coleman, M.; Pineau, F.; Javoy, M. Pyrohydrolysis-IRMS determination of silicate chlorine stable isotope compositions. Application to oceanic crust and meteorite samples. Chem. Geol. 2007, 242, 187-201. [CrossRef]

2. Baasner, A.; Schmidt, B.C.; Webb, S.L. The effect of chlorine, fluorine and water on the viscosity of aluminosilicate melts. Chem. Geol. 2013, 357, 134-149. [CrossRef]

3. Rude, P.D.; Aller, R.C. Fluorine mobility during early diagenesis of carbonate sediment: An indicator of mineral transfor-mations. Geochim. Cosmochim. Acta 1991, 55, 2491-2509. [CrossRef]

4. Rude, P.D.; Aller, R.C. Fluorine uptake by Amazon continental shelf sediment and its impact on the global fluorine cycle. Cont. Shelf Res. 1994, 14, 883-907. [CrossRef]

5. Wang, Q.; Makishima, A.; Nakamura, E. Determination of Fluorine and Chlorine by Pyrohydrolysis and Ion Chroma-tography: Comparison with Alkaline Fusion Digestion and Ion Chromatography. Geostand. Geoanal. Res. 2010, 34, 175-183. [CrossRef]

6. Kendrick, M.A. Halogens in seawater, marine sediments and the altered oceanic crust and lithosphere. In The Role of Halogens in Terrestrial and Extraterrestrial Geochemical Processes; Harlov, D., Aranovich, L., Eds.; Springer Geochemistry: Cham, Switzerland, 2018.

7. Yardley, B.W.D. 100th Anniversary Special Paper: Metal concentrations in crustal fluids and their relationship to ore formation Econ. Geol. 2005, 100, 613-632. [CrossRef]

8. He, T.; Wang, Z.; Hu, Z. Advances in analysis for halogens in geological materials. Earth Sci. 2021. Available online: https: / / kns.cnki.net/kcms/detail/42.1874.P.20210831.1143.004.html (accessed on 31 August 2021). (In Chinese).

9. Li, Y.; Jiang, S.; Yang, T. Br/Cl, I/Cl and chlorine isotopic compositions of pore water in shallow sediments: Implications for the fluid sources in the Dongsha area, northern South China Sea. Acta Oceanol. Sin. 2017, 36, 31-36. [CrossRef]

10. Martin, J.B. Nonconservative behavior of $\mathrm{Br}-/ \mathrm{Cl}$ - ratios during alteration of volcaniclastic sediments. Geochim. Cosmochim. Acta 1999, 63, 383-391. [CrossRef]

11. Oosting, S.E.; Von Damm, K.L. Bromide/chloride fractionation in seafloor hydrothermal fluids from 9-10 ${ }^{\circ}$ East Pacific Rise. Earth Planet. Sci. Lett. 1996, 144, 133-145. [CrossRef]

12. Von Damm, K.L.; Buttermore, L.G.; Oosting, S.E.; Bray, A.M.; Fornari, D.J.; Lilley, M.D.; Shanks, W.C., III. Direct observation of the evolution of a seafloor 'black smoker' from vapor to brine. Earth Planet. Sci. Lett. 1997, 149, 101-111. [CrossRef]

13. Gieskes, J.M.; Simoneit, B.R.T.; Goodfellow, W.D.; Baker, P.A.; Mahn, C. Hydrothermal geochemistry of sediments and pore waters in Escanaba Trough-ODP Leg 169. Appl. Geochem. 2002, 17, 1435-1456. [CrossRef]

14. Wu, S.F.; You, C.F.; Valsami-Jones, E.; Baltatzis, E.; Shen, M.L. Br/Cl and I/Cl systematics in the shallow-water hydrothermal system at Milos Island, Hellenic Arc. Mar. Chem. 2012, 140, 33-43. [CrossRef]

15. Li, H.; Hermann, J. The effect of fluorine and chlorine on trace element partitioning between apatite and sediment melt at subduction zone conditions. Chem. Geol. 2017, 473, 55-73. [CrossRef]

16. Langenauer, M.; Krähenbühl, U.; Furrer, V.; Wyttenbach, A. Determination of fluorine, chlorine, bromine and iodine in seven geochemical reference samples. Geostand. Newsl. 1992, 16, 41-44. [CrossRef]

17. Zhang, B.; Guo, Y.; Chen, J.; Jiang, X.; Wang, S.; Zheng, S. Occurrence characteristics and release potential of fluoride in sediment of DaiHai Lak. China Environ. Sci. 2020, 40, 1748-1756. (In Chinese)

18. Liu, Q.; Zhang, B.; Zhai, D.; Han, Z.; Chi, Q.; Nie, L.; Zhou, J.; Xu, S.; Liu, H.; Wang, W.; et al. Continental-scale distribution and source identification of fluorine geochemical provinces in drainage catchment sediment and alluvial soil of China. J. Geochem. Explor. 2020, 214, 106537. [CrossRef]

19. Shinonaga, T.; Ebihara, M.; Nakahara, H.; Tomura, K.; Heumann, K.G. Cl, Br and I in igneous standard rocks. Chem. Geol. 1994, 115, 213-225. [CrossRef]

20. Ozaki, H.; Ebihara, M. Determination of trace halogens in rock samples by radiochemical neutron activation analysis coupled with the k0-standardization method. Anal. Chim. Acta. 2007, 583, 384-391. [CrossRef] 
21. Sekimoto, S.; Ebihara, M. Accurate Determination of chlorine, bromine, and iodine in sedimentary rock reference samples by radiochemical neutron activation analysis and a detailed comparison with inductively coupled plasma mass spectrometry literature data. Anal. Chem. 2013, 85, 6336-6341. [CrossRef]

22. Sekimoto, S.; Ebihara, M. Accurate Determination of chlorine, bromine and iodine in U.S. Geological Survey geochemical reference materials by radiochemical neutron activation analysis. Geostand. Geoanal. Res. 2017, 41, 213-219. [CrossRef]

23. Sano, T.; Fukuoka, T.; Hasenaka, T. Determination of chlorine contents in Geological Survey of Japan reference materials by prompt gamma neutron activation analysis. Geostand. Geoanal. Res. 2004, 28, 443-448. [CrossRef]

24. Li, X.L.; Chen, X.; Ge, H.J.; Wu, Y.T.; Xian, X.L.; Han, W. XRFS determination of chlorine etc multi-elements in sea sediments with sample preparation by fusion. Phys. Test. Chem. Anal. 2011, 47, 1420-1423. (In Chinese)

25. Yuan, J.; Xia, C.; Liu, G.; Liu, X. Determination of F, Ca and other major elements in high fluoride concentration samples by X-Ray fluorescence spectrometry. Uranium Geol. 2016, 32, 175-179. (In Chinese)

26. Xia, C.; Jiang, Y.; Zheng, J.; Qian, H. XRFS determination of chlorine in geological samples. Phys. Test. Chem. Anal. 2017, 53, 775-779. (In Chinese)

27. A, L.; Zhang, P.; He, P.; Yang, Z.; Liang, Y.; Yang, Y. Determination of sulphur and fluorine in geological samples by X-ray fluorescence spectrometry. Chin. J. Inorg. Anal. Chem. 2019, 9, 50-53. (In Chinese)

28. Anazawa, K.; Tomiyasu, T.; Sakamoto, H. Simultaneous determination of fluorine and chlorine in rocks by ion chromatography in combination with alkali fusion and cation-exchange pretreatment. Anal. Sci. 2001, 17, 217-219. [CrossRef]

29. Michel, A.; Villemant, B. Determination of halogens (F, Cl, Br, I), sulfur and water in seventeen geological reference materials. Geostand. Newsl. J. Geostand. Geoanal. 2003, 27, 163-171. [CrossRef]

30. Shimizu, K.; Itai, T.; Kusakabe, M. Ion Chromatographic Determination of Fluorine and Chlorine in Silicate Rocks Following Alkaline Fusion. Geostand. Geoanal. Res. 2006, 30, 121-129. [CrossRef]

31. Balcone-Boissard, H.; Michel, A.; Villemant, B. Simultaneous Determination of Fluorine, Chlorine, Bromine and Iodine in Six Geochemical Reference Materials Using Pyrohydrolysis, Ion Chromatography and Inductively Coupled Plasma-Mass Spectrometry. Geostand. Geoanal. Res. 2009, 33, 477-485. [CrossRef]

32. Shimizu, K.; Suzuki, K.; Saitoh, M.; Konno, U.; Kawagucci, S.; Ueno, Y. Simultaneous determinations of fluorine, chlorine, and sulfur in rock samples by ion chromatography combined with pyrohydrolysis. Geochem. J. 2015, 9, 113. [CrossRef]

33. Bianchini, G.; Brombin, V.; Marchina, C.; Natali, C.; Godebo, T.R.; Rasini, A.; Salani, G.M. Origin of Fluoride and Arsenic in the Main Ethiopian Rift Waters. Minerals 2020, 10, 453. [CrossRef]

34. Ro, S.; Hur, S.D.; Hong, S.; Chang, C.; Moon, J.; Han, Y.; Jun, S.J.; Hwang, H.; Hong, S. An improved ion chromatography system coupled with a melter for highresolution ionic species reconstruction in Antarctic firn cores. Microchem. J. 2020, $159,105377$. [CrossRef]

35. Li, T.; Min, H.; Li, C.; Yan, C.; Zhang, L.; Liu, S. Simultaneous Determination of Trace Fluorine and Chlorine in Iron Ore by Combustion-Ion Chromatography (C-IC). Anal. Lett. 2021, 54, 2498-2508. [CrossRef]

36. Pereira, L.S.F.; Enders, M.S.P.; Iop, G.D.; Mello, P.A.; Flores, E.M.M. Determination of Cl, Br and I in soils by ICP-MS: Microwaveassisted wet partial digestion using $\mathrm{H}_{2} \mathrm{O}_{2}$ in an ultra-high pressure system. J. Anal. At. Spectrom. 2018, 33, 649-657. [CrossRef]

37. He, T.; Hu, Z.; Zhang, W.; Chen, H.; Liu, Y.; Wang, Z.; Hu, S. Determination of Cl, Br, and I in Geological Materials by Sector Field Inductively Coupled Plasma Mass Spectrometry. Anal. Chem. 2019, 91, 8109-8114. [CrossRef] [PubMed]

38. Zhang, W.; Hu, Z. Recent advances in sample preparation methods for elemental and isotopic analysis of geological samples. Spectrochim. Acta B 2019, 160, 105690. [CrossRef]

39. Yin, X.; Wang, X.; Chen, S.; Ma, Y.; Kun, G.; Zeng, Z. Trace Element Determination in Sulfur Samples Using a Novel Digestion Bomb Prior to ICP-MS Analysis. Atom. Spectrosc. 2018, 39, 137-141. [CrossRef]

40. Wang, X.; Yin, X.; Zeng, Z.; Chen, S. Multi-element Analysis of Ferromanganese Nodules and Crusts by Inductively Coupled Plasma Mass Spectrometry. Atom. Spectrosc. 2019, 40, 153-160. [CrossRef]

41. Tan, X.; Wang, Z. General High-Pressure Closed Acidic Decomposition Method of Rock Samples for Trace Element Determination Using Inductively Coupled Plasma Mass Spectrometry. J. Anal. Chem. 2020, 75, 1295-1303. 